\title{
Correlation between stabilizer consumption and degree of polymerization of thermally upgraded paper aged in insulating natural ester and insulating mineral oil
}

\author{
Larissa Mildemberger ${ }^{1,2}$, Mario Carlos Andreoli ${ }^{3}$, Guilherme Cunha da Silva ${ }^{1}$, Heloisa Nunes da Motta ${ }^{1}$, \\ Joseane Valente Gulmine ${ }^{1}$ and Marilda Munaro',2* \\ 'Instituto de Tecnologia para o Desenvolvimento - LACTEC, Curitiba, PR, Brazil \\ 2Programa de Pós-graduação em Engenharia e Ciência de Materiais - PIPE, \\ Universidade Federal do Paraná - UFPR, Curitiba, PR, Brazil \\ ${ }^{3}$ Companhia de Transmissão de Energia Elétrica Paulista - CTEEP, São Paulo, SP, Brazil \\ *marilda@lactec.org.br
}

\begin{abstract}
Insulating paper holds significant importance in the insulation system of power transformers, and thus, its degradation is the subject of many studies. A successful evaluation of the degradation rate of such paper contributes to reducing downtime and avoiding equipment failure. In this work, samples of thermally upgraded paper were thermally aged in insulating natural ester (INE) and insulating mineral oil (IMO) and were evaluated by degree of polymerization (DP) and FTIR-ATR. It was possible to identify characteristic bands of dicyandiamide, an inhibitory compound of the thermal degradation of the paper, and to establish a correlation between the decrease in DP and the consumption of dicyandiamide during aging, which was observed to develop in three distinct steps for both IMO and INE.
\end{abstract}

Keywords: thermally upgraded paper, thermal degradation, insulating natural ester, insulating mineral oil.

\section{Introduction}

Transformers are essential equipment in modern electrical systems, responsible for the necessary variations in voltages for interconnection. An important part of a transformer is its insulation system, which is basically composed of an insulating fluid and an insulating solid ${ }^{[1]}$. This insulating function has been well performed by insulating mineral oil (IMO) and insulating paper for more than a century ${ }^{[2]}$.

Because IMO is derived from petroleum, a non-renewable resource, new alternatives for insulating fluids for the electrical sector have been sought. Insulating natural esters (INEs) show faster biodegradability than IMO and are derived from renewable resources; thus, INEs are strong candidates for replacing $\mathrm{IMO}^{[3]}$.

Solid insulation is performed by insulating paper based on $90 \%$ cellulose coupled with hemicellulose, lignin and traces of pentose; this insulating paper is fundamentally important because it cannot be replaced while a transformer is in service, and thus, the paper determines the useful lifetime of the equipment ${ }^{[4]}$.

The degree of polymerization (DP) is used to evaluate the degradation of insulation paper; it indicates the average number of $\alpha$-D-glucopyranose units in a cellulose molecule. The DP of fresh paper is greater than 1000 , and the end of the lifetime of a transformer is reached when the DP of the insulating paper reaches approximately 200 , the moment when the paper no longer exhibits mechanical resistance and the paper's insulating properties are compromised ${ }^{[5]}$. This DP decrease is explained by the breaking of $1.4-\beta$ glycosidic bonds in glucose monomers of cellulose chains by hydrolysis, oxidation and pyrolysis. The most significant mechanism for cellulose degradation process in transformers is the hydrolysis. Several studies have investigated the correlation between cellulose depolymerization rate, activation energy for breaking glycosidic bonds and paper lifetime ${ }^{[6-9]}$.

The production of thermally upgraded paper (TU) started in the 1950s to reduce the rate of thermal degradation of the paper ${ }^{[10]}$. Two methods for stabilizing the paper were proposed: (i) the chemical modification of the cellulose via cyanoethylation and acetylation and (ii) the addition of nitrogen compounds to protect the cellulose from oxidation - inhibitory compounds such as urea, melamine, dicyandiamide and polyacrylamide. Due to environmental concerns, chemical modification by cyanoethylation and acetylation is no longer performed ${ }^{[11]}$.

By thermally accelerating the aging of kraft (KP) and thermally upgraded paper in IMO, Martins ${ }^{[10]}$ observed a lower thermal degradation rate for TU than for KP, possibly due to the neutralization of the acid compounds formed during the degradation process of the insulating system by the nitrogen bases and the reduction of the effect of pyrolysis due to the reactions occurring between the inhibitory compounds and water.

Authors such as McShane et al. ${ }^{[12]}$, Yang et al. ${ }^{[13]}$ and Frimpong et al. ${ }^{[14]}$, comparing the degradation of KP in IMO and INE, observed the preservation of paper aged in INE. The authors concluded that this protection can be attributed to three main factors: (i) the INE can support hydrolysis and consume the available water inside the insulation system, reducing the potential for the hydrolysis of the paper; (ii) the INE can dry the insulating paper due to the affinity between 
the esters and water and due to the high degree of solubility of the water in this insulating fluid compared to that in IMO; and (iii) the progression of the so-called transesterification process, through which cellulose molecules are modified by the substitution of $\mathrm{OH}$ - groups in the cellulose by ester groups, which are larger and more stable, increasing the paper's lifetime. However, only a few studies have been dedicated to examining the aging of thermally upgraded paper in INE.

In this work, the consumption of the inhibitor compound used in upgraded paper was monitored by the FTIR-ATR technique, and a correlation between the DP of the paper aged in IMO and INE was established.

\section{Experimental}

\subsection{Materials}

The following materials were used: insulating thermally upgraded paper for electrical equipment from Isoeletri; insulating mineral oil AV-60IN Petrobras, with paraffin chains $48 \%$, naphthenic chains $48 \%$ and aromatics $4 \%$, with $17 \mathrm{ppm}$ of water content; insulating natural ester soybean base Envirotemp FR3 Cargill, with 54 ppm of water content; and electrolytic copper foils.

\subsection{Sample aging}

The paper was cut into pieces measuring $4 \mathrm{~m}$ in length and $15 \mathrm{~mm}$ in width, rolled up and dried at $100^{\circ} \mathrm{C}$ for 2 hours in a vacuum oven. Electrolytic copper foils measuring $20 \times 1 \times 0.2 \mathrm{~mm}$ were prepared by first polishing them with coarse sandpaper and then with finer sandpaper. The foils were cleaned using cotton soaked in acetone and silicon carbide polishing. The copper was used in order to simulate the aging conditions of the transformer.

Samples of the oil $(250 \mathrm{~mL})$ were placed in biochemical oxygen demand (BOD) flasks, and $\mathrm{N}_{2}$ was bubbled into each flask for 10 minutes to eliminate $\mathrm{O}_{2}$; then, a dried paper strip and the copper foil were added and the flasks were closed. The flasks were placed in an oven at $100{ }^{\circ} \mathrm{C}$. The samples were taken at 15, 30, 33, 36, 39, 42 and 45 days of aging. After being removed from the oven, the samples were left in a dark environment for 24 hours to reach room temperature.

\subsection{Oil extraction}

To facilitate the tests of the paper after aging, the impregnated oil was extracted via an ASE200 - Accelerated Solvent Extractor from Dionex, using hexane as solvent, at a temperature of $50{ }^{\circ} \mathrm{C}$ and pressure of 500 psi. After the extraction, the paper was dried in an oven at $75^{\circ} \mathrm{C}$ for 1 hour and placed in a desiccator prior to analysis.

\subsection{Degree of polymerization}

The DP was determined by the viscometric method according to the Brazilian standard ABNT NBR IEC 60450:2009 ${ }^{[15]}$, using a capillary viscometer immersed in a water bath at $20^{\circ} \mathrm{C} \pm 0.1{ }^{\circ} \mathrm{C}$ and a 1 mol. $\mathrm{L}^{-1}$ aqueous solution of copper(II) hydroxide bis (ethylenediamine) from Aldrich . The paper sample was milled, dried and weighted. After this, it was solved in copper(II) hydroxide bis (ethylenediamine) for $16 \mathrm{~h}$ with $\mathrm{N}_{2}$ bubbling and the viscosity of this solution was measured.

\subsection{Dicyandiamide index}

FTIR analysis of the dicyandiamide content in the paper was performed by the reflectance technique, in a horizontal ATR accessory from Graseby Specac, using a rectangular ZnSe crystal measuring $10 \times 50 \mathrm{~mm}$. Paper samples were positioned directly on the accessory, and pressure was applied to enhance the contact between the crystal and the paper surfaces. The instrument used for analysis was a Vertex 70 Infrared Spectrophotometer from Bruker with a resolution of $4 \mathrm{~cm}^{-1} ; 32$ sweeps were performed over the region between $4000 \mathrm{~cm}^{-1}$ and $650 \mathrm{~cm}^{-1}$.

The calculus of dicyandiamide index was made by dividing the integral of bands between $2194-2154 \mathrm{~cm}^{-1}$, the doublet from dicyandiamide, by the integral of band of $\mathrm{C}-\mathrm{O}$ bond of cellulose between $1188-914 \mathrm{~cm}^{-1}$ (Equation 1).

$$
\text { dicyandiamide index }=\frac{\begin{array}{c}
\text { int egral of the bands between } \\
\text { int egral of the band between } \\
1188-914 \mathrm{~cm}^{-1}
\end{array}}{2245-2040 \mathrm{~cm}^{-1}}
$$

\section{Results and discussion}

\subsection{Degree of polymerization}

Figure 1 shows the DP of the paper decreasing with aging time and there was no significant difference between the paper aged in IMO and aged in INE, indicating was not reduction in the degradation rate of the paper in INE under the conditions applied in the present work, how as suggested by some authors ${ }^{[12-14]}$. After 15 days of aging, the DP of the paper decreased but remained close to 1000 , a value still considered suitable for the utilization of the paper. The DP value continued to decrease until the aging time reached between 33 and 42 days, during which the degradation rate of the paper decreased, reaching a type of plateau. During this time, the dicyandiamide most likely protected the cellulose chains, decreasing the rate of chain breakage

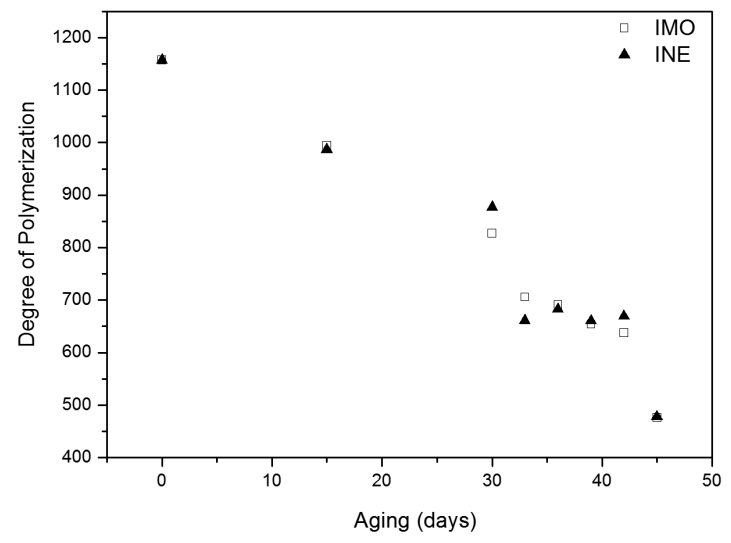

Figure 1. DP of the samples aged in natural ester (INE) and mineral oil (IMO) versus aging time. 
and causing the degree of polymerization to fluctuate to a lower degree. At 45 days after the beginning of the aging process, the DP was reduced to $50 \%$ of its initial value, in both IMO and INE, indicative that the mechanical properties of the material could started to be compromised. According to Shroff and Stannett ${ }^{[16]}$ the reduction of $50 \%$ of the value of DP may be related to a decrease of approximately $25 \%$ of tensile strength.

\subsection{Dicyandiamide index}

The FTIR spectrum of fresh insulating paper is shown in Figure 2, which demonstrates bands related to cellulose, the paper's main component, as well as the characteristic bands of the inhibitor compound.

The wide band at $3339 \mathrm{~cm}^{-1}$ can be attributed to the stretching vibration of the $\mathrm{OH}$ bond of hydroxyl groups. The band at $2918 \mathrm{~cm}^{-1}$ is due to the stretching of the C-H bond. The signal associated with the bending of $\mathrm{CH}_{2}$ bonds occurs at $1425 \mathrm{~cm}^{-1}$. The signal corresponding to the asymmetric stretching of the $\mathrm{C}-\mathrm{O}-\mathrm{C}$ bond is observed at $1159 \mathrm{~cm}^{-1}$, and that associated with the stretching of the C-O bond occurs at $1027 \mathrm{~cm}^{-1}$. The band at $896 \mathrm{~cm}^{-1}$ is possibly related to $\beta$-glycosidic bonds, which are characteristic of the cellulose molecule ${ }^{[17]}$.

The bands that appear in the regions of $1658 \mathrm{~cm}^{-1}$ and $1560 \mathrm{~cm}^{-1}$ can be attributed, respectively, to the C-N bonds and to the deformation of the N-H bonds of primary amines ${ }^{[18]}$. The doublet in the $2194-2154 \mathrm{~cm}^{-1}$ region is attributed to the resonance between $\mathrm{C} \equiv \mathrm{N}$ and $\mathrm{C}=\mathrm{NH}$, a characteristic absorption band of the dicyandiamide compound because, among the nitrogen compounds used as inhibitors in the insulating paper upgrading process (urea, guanidine, acrylonitrile, melamine and dicyandiamide), only the dicyandiamide compound shows a doublet near $2200 \mathrm{~cm}^{-1}$ in its FTIR spectrum $^{[19]}$. The intensity of the dicyandiamide doublet decrease for both oils in aged paper spectrum.

The inhibitor cannot be directly quantified solely by the integration of the band area of the compound's absorption region because the ATR technique is highly affected by the contact between the sample and the crystal; therefore, the consumption of dicyandiamide was analyzed by the band ratio technique, resulting in semi-quantitative analysis (Figure 3). It can be observed that the inhibitor content in the aged paper, for both IMO and INE, decreased with aging time, indicating that the dicyandiamide was consumed during thermal aging. An increase in the consumption rate of dicyandiamide was indicated by an abrupt change in the slope of the curve beginning at 33 days of aging, corroborating the plateau in the DP behavior shown in Figure 1, with the decrease in the rate of breakage of the cellulose chains.

The samples aged in INE showed slight dispersion in the data, possibly due to the fluid's polarity and to the affinity of the dicyandiamide nitrile group for the insulating solid and liquid materials, which can promote the partition of this stabilizing agent between the paper and INE, as dicyandiamide is not chemically bound to cellulose. Again, no large differences were observed between the samples aged in IMO and INE over the same aging time, which confirmed that there was no reduction in the rate of consumption of the additive in paper aged in ester; this finding may indicate that

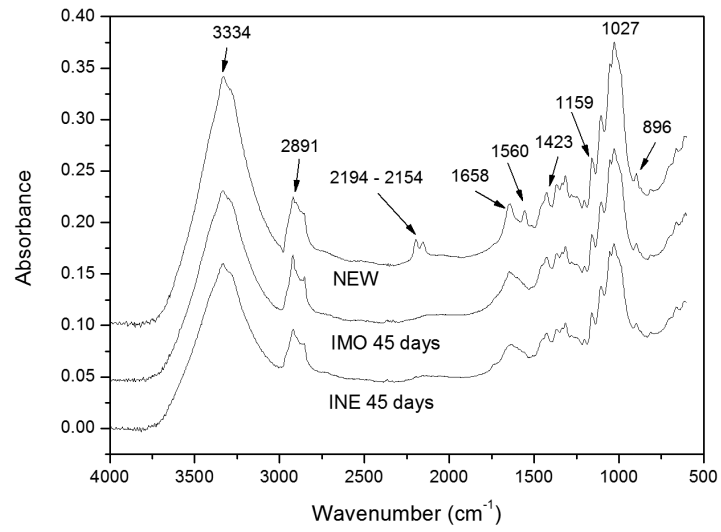

Figure 2. FTIR-ATR spectra of thermally upgraded paper (TU), new and after 45 days aging in IMO and ENI.

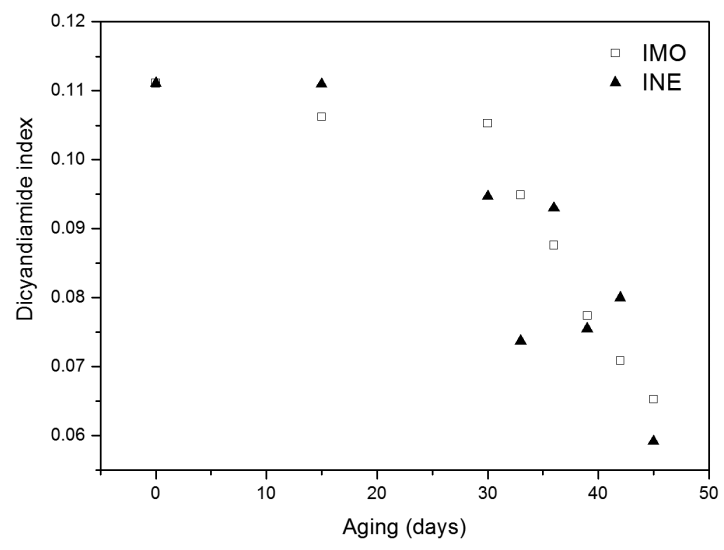

Figure 3. Dicyandiamide index during aging time.

INE does not protect the paper from degradation under the effects of the inhibitor. Yang et al ${ }^{[20]}$ obtained similar results.

\subsection{Correlation between DP and Dicyandiamide index}

Figure 4 shows the behavior of the DP in relation to the consumption of dicyandiamide. As in the study by Morais et al. ${ }^{[19]}$, the inhibitor is observed to operate in three steps. The first step occurs when the paper's DP is above 800 and the bonds that are not protected by the inhibitor can be broken, which generally begins to take place during the drying of the paper. At this stage, in the unprotected portions of the paper, acid-catalyzed hydrolysis can occur via small molecules (formic acid, acetic acid), which are readily absorbed in the paper's structure causing oxidation of the oil and paper; this process breaks glycosidic bonds and decreases the DP. The oxidation of the paper may also occur through the formation of hydroperoxide radicals, which attack and open glucose rings, forming acids and aldehydes and also reducing the size of the cellulose chains. A certain amount of dicyandiamide is also most likely consumed through Maillard reactions ${ }^{[21]}$ between primary amines (as is the case with dicyandiamide) and aldehydes (which are formed during degradation of the oil and paper). Furthermore, dicyandiamide acts as a base and reacts with 


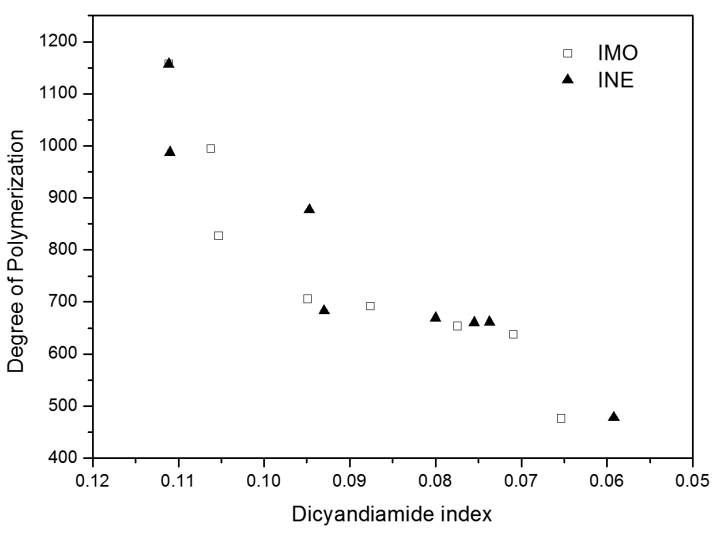

Figure 4. Degree of polymerization (DP) as a function of dicyandiamide index.

acids in the presence of water and temperature to form ammonia and $\mathrm{CO}_{2}$, thereby consuming water. Ammonia also acts as a primary amine and reacts with aldehydes ${ }^{[10]}$.

Second, the inhibitor begins to be consumed, but no significant change in DP is observed, as evidenced by the formation of a plateau between 33 and 42 days of aging. During this period, the paper is being protected while the inhibitor is being consumed by Maillard reactions and acid hydrolysis.

In the third stage, approximately half of the stabilizer has already been consumed and the DP reaches one-third of its initial value at 45 days of accelerated aging.

As indicated by the curves shown in Figure 4, the type of insulating fluid used did not affect the degradation processes of thermally upgraded paper in any relevant way; in fact, the effect of the stabilizing additives in the test systems was observed to be more significant. Probably when the dicyandiamide is fully consumed the paper degradation kinetics will be slower in ENI.

\section{Conclusions}

The modification of electrical insulating paper during the upgrading process was confirmed by the FTIR-ATR technique via the identification of bands related to dicyandiamide in the regions of $1658 \mathrm{~cm}^{-1}, 1560 \mathrm{~cm}^{-1}$ and $2194-2154 \mathrm{~cm}^{-1}$.

It was possible to correlate the consumption of dicyandiamide during the paper aging process and the decrease in the DP. In addition, the paper's behavior in natural ester was observed to be very similar to that in mineral oil.

Three different regions were observed for the consumption of dicyandiamide as a function of aging, indicating that changes in the degradation mechanism took place as the inhibitor was consumed. Additionally, a slight dispersion in the data was observed for the insulating natural ester system, most likely due to the fluid's polar nature, causing the partition of dicyandiamide between the paper and the ester.

Finally, it was observed that the type of insulating fluid used exerts a minor effect on the degradation of thermally upgraded paper while the dicyandiamide is not fully consumed.

\section{Acknowledgements}

The authors sincerely acknowledge CTEEP (Companhia de Transmissão de Energia Elétrica Paulista), CNPq (the Brazilian National Council of Scientific and Technological Development) for the benefit of the Law 8010/90, UFPR and LACTEC for their financial support.

\section{References}

1. Fofana, I., Bouslimi, H., Hemmatjou, C., Volat, K., \& Tahiri, K. (2014). Relationship between static electrification of transformer oils with turbidity and spectrophotometry measurements. International Journal of Electrical Power \& Energy Systems, 54, 38-44. http://dx.doi.org/10.1016/j.ijepes.2013.06.037.

2. Prevost, T. A. (2005). Thermally upgraded insulation in transformer. In Proceedings of Electrical Insulation Conference and Electrical Manufacturing Expo (pp. 120-125). Indianapolis: IEEE.

3. Ciuriuc, A., Vihacencu, M. S., Dumitran, L. M., \& Notingher, P. V. (2012). Comparative study on power transformers vegetable oil and mineral oil ageing. In Proceedings of International Conference on Applied and Theoretical Electricity (pp. 1-6). Craiova: IEEE.

4. Martins, M. A. G. (2007). Furfuraldeído: um indicador prático da degradação térmica do papel kraft de transformadores. Ciência e Tecnologia dos Materiais, 19(1-2), 25-33.

5. Liland, K. B., Ese, M. H. G., Selsbak, C. M., \& Lundgaard, L. (2011). Ageing of oil impregnated thermally upgraded papers. In Proceedings of IEEE International Conference on Dielectric Liquids (pp. 1-5). Trondheim: IEEE.

6. Jalbert, J., Gilbert, R., Tétreault, P., Morin, B., \& LessardDéziel, D. (2007). Identification of a chemical indicator of the rupture of 1,4-beta-glycosidic bonds of cellulose in an oil-impregnated insulating paper system. Cellulose, 14(4), 295-309. http://dx.doi.org/10.1007/s10570-007-9124-1.

7. Gilbert, R., Jalbert, J., Tétreault, P., Morin, B., \& Denos, Y. (2009). Kinetics of the production of chain-end groups and methanol from the depolymerization of cellulose during the ageing of paper/oil systems. Part 1: standard wood kraft insulation. Cellulose, 16(2), 327-338. http://dx.doi.org/10.1007/ s10570-008-9261-1.

8. Gilbert, R., Jalbert, J., Duchesne, S., Tetreault, P., Morin, B., $\&$ Denos, Y. (2010). Kinetics of the production of chain-end groups and methanol from the depolymerization of cellulose during the ageing of paper/oil systems. Part 2: thermallyupgraded insulating papers. Cellulose, 17(2), 253-269. http:// dx.doi.org/10.1007/s10570-009-9365-2.

9. Setnescu, R., Badicu, L. V., Dumitran, L. M., Notingher, P. V., \& Setnescu, T. (2014). Thermal lifetime of cellulose insulation material evaluated by an activation energy based method. Cellulose, 21(1), 823-833. http://dx.doi.org/10.1007/ s10570-013-0087-0.

10. Martins, M. A. (2007). Monitorização da degradação térmica do papel isolante usado em transformadores: papel "thermally upgraded" versus papel kraft. Ciência e Tecnologia dos Materiais, 19(1-2), 14-18.

11. Prevost, T. A. (2009). Dielectric properties of natural esters and their influence on transformer insulation system design and performance: an update. In Proceedings of Power \& Energy Society General Meeting (pp. 1-7), Calgary: IEEE.

12. McShane, C. P., Rapp, K. J., Corkran, J. L., Gauger, G. A., \& Luksich, J. (2001). Aging of paper insulation in natural ester dielectric fluid. In Proceedings of Transmission and Distribution Conference and Exposition (Vol. 2, pp. 675-679). Atlanta: IEEE. 
13. Yang, L., Liao, R., Caixin, S., \& Zhu, M. (2011). Influence of vegetable oil on the thermal aging of transformer paper and its mechanism. IEEE Transactions on Dielectrics and Electrical Insulation, 18(3), 692-700. http://dx.doi.org/10.1109/ TDEI.2011.5931054.

14. Frimpong, G. K., Oommen, T. V., \& Asano, R. (2011). A survey of aging characteristics of cellulose insulation in natural ester and mineral oil. IEEE Electrical Insulation Magazine, 27(5), 36-48. http://dx.doi.org/10.1109/MEI.2011.6025367.

15. Associação Brasileira de Normas Técnicas - ABNT. (2009). ABNT NBR IEC 60450: medição do grau de polimerização viscosimétrico médio de materiais celulósicos novos e envelhecidos para isolação elétrica. Rio de Janeiro.

16. Shroff, D. H., \& Stannett, A. W. (1985). A review of paper aging in power transformers. IEE Proceedings. Part C. Generation, Transmission and Distribution, 132(6), 312-319. http://dx.doi. org/10.1049/ip-c.1985.0052.

17. Yu, X., Tong, S., Ge, M., Wu, L., Zuo, J., Cao, C., \& Song, W. (2013). Synthesis and characterization of multi-aminofunctionalized cellulose for arsenic adsorption. Carbohydrate Polymers, 92(1), 380-387. http://dx.doi.org/10.1016/j. carbpol.2012.09.050. PMid:23218309.
18. Urreaga, J. M., \& Orden, M. U. (2007). Modification of cellulose with amino compounds: a fluorescence study. Carbohydrate Polymers, 69(1), 14-19. http://dx.doi.org/10.1016/j. carbpol.2006.08.019.

19. Morais, R. M., Mannheimer, W. A., Carballeira, M., \& Noualhaguet, J. C. (1999). Furfural analysis for assessing degradation of thermally upgraded papers in transformer insulation. IEEE Transactions on Dielectrics and Electrical Insulation, 6(2), 159-163. http://dx.doi.org/10.1109/94.765905.

20. Yang, L., Liao, R., Sun, C., \& Sun, H. (2008). Study on the influence of natural ester on thermal ageing characteristics of oil-paper in power transformer. In Proceedings of International Conference on High Voltage Engineering and Application (pp. 437-440). Chongqing: IEEE.

21. Lundgaard, L. E., Hansen, W., Linhjell, D., \& Painter, T. J. (2004). Aging of oil-impregnated paper in power transformers. IEEE Transactions on Power Delivery, 19(1), 230-239. http:// dx.doi.org/10.1109/TPWRD.2003.820175.

Received: Nov. 14, 2014

Revised: June 25, 2015 Accepted: Sept. 11, 2015 